\title{
Design and Analysis of a Stator-Doubly-Fed Doubly-Salient Permanent-Magnet Machine for Automotive Engines
}

\author{
K. T. Chau ${ }^{1}$, Y. B. Li ${ }^{2}$, J. Z. Jiang ${ }^{2}$, and Chunhua Liu ${ }^{1}$ \\ ${ }^{1}$ Department of Electrical and Electronic Engineering, The University of Hong Kong, Hong Kong, China \\ ${ }^{2}$ Department of Automation, Shanghai University, Shanghai 200072, China
}

\begin{abstract}
This paper presents a new outer-rotor stator-doubly-fed doubly-salient permanent-magnet (SDF-DSPM) machine, which can be used as the integrated starter-generator for modern automobiles and mild hybrid electric vehicles. The key of the proposed machine is to incorporate both de field windings and PMs in the inner stator, hence, offering a compact arrangement of hybrid field excitations. While armature windings are located in salient poles of the outer stator, the outer rotor is simply composed of salient poles without windings or PMs. In addition, an air bridge is purposely created in shunt with each PM in the inner stator, hence, providing an amplification effect for flux regulation. With this idea, the air-gap flux can be strengthened or weakened with a small dc field current so that the electromagnetic torque and induced electromotive force (EMF) can be effectively regulated. The newly designed SDF-DSPM machine is analyzed by using both the magnetic circuit model and finite element method, and assessed by performance simulation.
\end{abstract}

Index Terms-Finite element method, hybrid field, integrated starter-generator, permanent-magnet machine.

\section{INTRODUCTION}

$\mathbf{I}$ NSTEAD of using separate machines for cold cranking and battery charging, the concept of integrated starter-generator (ISG) is becoming attractive for modern automobiles and mild hybrid electric vehicles (HEVs) [1]. Because of the requirements of very high starting torque (up to four times the rated torque) for cold cranking, as well as constant output voltage over a very wide speed range (25\% to four times the base speed) for battery charging, the design of this ISG is challenging. Recently, the permanent magnet (PM) synchronous machine has been utilized for ISG application, since it inherently offers high torque density and high efficiency [2]. However, because of uncontrollable PM flux, it cannot maintain high efficiency or constant output voltage over the wide speed range. To enable flux control, the idea of stator-doubly-fed doubly-salient permanent-magnet (SDF-DSPM) machine has been proposed [3]. Since the SDF-DSPM machine incorporates the unique features of the DSPM machine [4] and the SDFDS machine [5], it offers the merits of flux controllability and high robustness. However, it involves a bulky structure to accommodate two kinds of excitations, leading to difficulty in manufacturing.

In this paper, a new outer-rotor SDF-DSPM machine is proposed for automotive engines. Different from the conventional automotive electrical system in which the starter and generator are separately employed, this ISG system serves both cold cranking and battery charging to achieve the desired performance for automobiles and mild HEVs. The newly designed SDF-DSPM machine will be analyzed by using both the magnetic circuit model and finite element method (FEM). Hence, performance simulation will be conducted to assess the proposed machine.

Digital Object Identifier 10.1109/TMAG.2006.879440

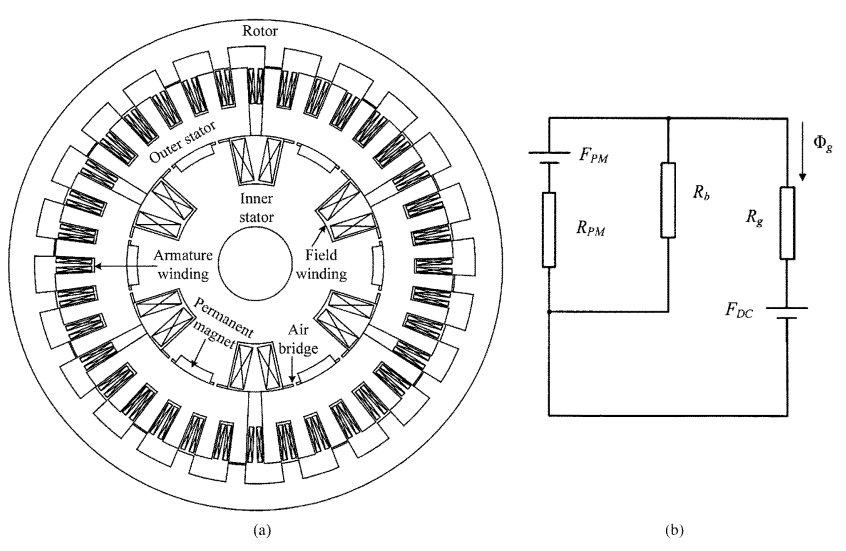

Fig. 1. Proposed SDF-DSPM machine. (a) Structure. (b) Equivalent magnetic circuit.

\section{MACHINE DESIGN AND ANALYSIS}

The structure of the proposed machine is shown in Fig. 1(a) in which there are both PM and dc field winding excitations, as well as salient poles in both the stator and rotor. Different from that in [3], the proposed SDF-DSPM machine adopts a new double-stator outer-rotor topology. Namely, armature windings are located in salient poles of the outer stator, and the outer rotor is simply composed of salient poles without windings or PMs. While deriving from an outer-rotor DSPM machine with 36 stator poles and 24 rotor poles, the proposed machine newly incorporates de field windings in shunt with PMs in the inner stator, and creates air bridges in shunt with PM pieces. The dc field windings provide flexible flux control, including both flux strengthening and weakening. The air bridges function to bypass the PM flux when two field excitations are opposite, hence, amplifying the effect of flux weakening.

The principle of operation of this SDF-DSPM machine is similar to that of the DSPM machine [4], except that the flux is controllable. When the air-gap flux linkage increases with the 
rotor position angle, a positive current is applied to the armature windings, resulting in a positive torque. When the flux linkage decreases, a negative current is applied, also resulting in a positive torque. Thus, when the SDF-DSPM machine works as a starter, the dc field windings are excited to produce additional flux in the same direction as the PM flux, hence, strengthening the air-gap flux linkage to achieve very high starting torque for cold cranking. On the other hand, when the proposed machine works as a generator, the air-gap flux linkage is regulated by varying the dc field current in such a way that the PM flux is weakened or strengthened by the dc field, hence, realizing the desired constant output voltage over a wide speed range.

The choice of pole numbers of the proposed machine is governed by $N_{s}=4 m p$ and $N_{r}=2 N_{s} / m$, where $N_{s}$ is the number of stator poles, $N_{r}$ is the number of rotor poles, $m$ is the number of phases, and $p$ is the number of pole-pairs of the dc field windings. For the proposed machine, $m=3$ and $p=3$ are selected, hence, resulting in $N_{s}=36$ and $N_{r}=24$. If $p$ is too large, $N_{r}$ will be very large, which will significantly increase the operating frequency and, hence, the iron loss. On the contrary, if $p$ is too small, the operating frequency will be insufficient to limit the rectified output voltage ripple.

The proposed machine adopts the outer-rotor topology instead of the conventional inner-rotor one. There are two main reasons. First, if the conventional inner-rotor topology is used, the stator yoke needs to be significantly enlarged to accommodate both the PMs and dc field windings, which was the problem in [3]. However, if the outer-rotor topology is adopted, the inner stator (the part beneath the armature windings) can be fully utilized to accommodate both the PMs and dc field windings, hence, minimizing the overall size. Second, if adopting the conventional topology, both the PMs and dc field windings in the stator have high flux leakage as suffered in [3]. However, if adopting the outer-rotor topology, both the PMs and dc field windings are embraced by the rotor, hence, solving the problem of high flux leakage. However, the outer-rotor topology has the drawback of thermal dissipation, since it is more difficult to effectively cool the inside stators. Fortunately, this drawback is not a significant problem for this ISG application because the stators are highly loaded at the instant of cold cranking only.

Due to the additional dc field windings, the proposed SDFDSPM machine definitely offers a lower power density than the DSPM machine. It is really a tradeoff between the ability of flux control and the reduction of power density. Since the ability of flux control is the key to produce very high starting torque for cold cranking and constant output voltage over a very wide speed range for battery charging, it is worthwhile to accept the reduction of power density for ISG application.

To illustrate the ability and the range of controllable flux, an equivalent magnetic circuit of the proposed machine at no load is modeled as shown in Fig. 1(b), where $R_{\mathrm{PM}}$ is the PM reluctance, $R_{b}$ is the air-bridge reluctance, $R_{g}$ is the air-gap reluctance, $F_{\mathrm{dc}}$ is the dc field winding $\mathrm{MMF}$, and $F_{\mathrm{PM}}$ is the PM MMF. From Fig. 1(b), the air-gap flux $\Phi_{g}$ is given by

$$
\Phi_{g}=\frac{F_{\mathrm{dc}}\left(R_{b}+R_{\mathrm{PM}}\right)+F_{\mathrm{PM}} R_{b}}{R_{b} R_{g}+R_{\mathrm{PM}} R_{g}+R_{b} R_{\mathrm{PM}}}
$$

TABLE I

SELECTION OF RELUCTANCE RATIO

\begin{tabular}{ccc}
\hline$R_{P M} / R_{b}$ & $F_{D C-} / F_{P M}$ & $F_{D C+} / F_{P M}$ \\
\hline 10 & $2 / 33$ & $2 / 11$ \\
8 & $2 / 27$ & $2 / 9$ \\
7 & $1 / 12$ & $1 / 4$ \\
6 & $2 / 21$ & $2 / 7$ \\
5 & $1 / 9$ & $1 / 3$ \\
4 & $2 / 15$ & $2 / 5$ \\
3 & $1 / 6$ & $1 / 2$ \\
2 & $2 / 9$ & $2 / 3$ \\
1 & $1 / 3$ & 1 \\
\hline
\end{tabular}

TABLE II

Key DESIGN DATA

\begin{tabular}{ll}
\hline Rated voltage & $220 \mathrm{~V}$ \\
Rated power & $2 \mathrm{~kW}$ \\
Speed range & $0 \sim 4000 \mathrm{rpm}$ \\
Number of phases & 3 \\
Number of stator poles & 36 \\
Number of rotor poles & 24 \\
Number of turns per armature coil & 46 \\
Number of turns per field coil & 150 \\
Rotor outside diameter & $270.0 \mathrm{~mm}$ \\
Rotor inside diameter & $221.2 \mathrm{~mm}$ \\
Stator outside diameter & $220.0 \mathrm{~mm}$ \\
Stack length & $80.0 \mathrm{~mm}$ \\
\hline
\end{tabular}

Hence, it yields two design equations

$$
\begin{aligned}
& \frac{F_{\mathrm{dc}+}}{F_{\mathrm{PM}}}=\left(\frac{\Phi_{g+}}{\Phi_{g 0}}-1\right) /\left(\frac{R_{\mathrm{PM}}}{R_{b}}+1\right) \\
& \frac{F_{\mathrm{dc}-}}{F_{\mathrm{PM}}}=\left(1-\frac{\Phi_{g-}}{\Phi_{g 0}}\right) /\left(\frac{R_{\mathrm{PM}}}{R_{b}}+1\right)
\end{aligned}
$$

where $\Phi_{g 0}$ is the air-gap flux at $F_{\mathrm{dc}}=0, F_{\mathrm{dc}-}$, and $\Phi_{g-}$ are under flux weakening, and $F_{\mathrm{dc}}+$ and $\Phi_{g+}$ are under flux strengthening. For the given air-gap flux range of $\left(\Phi_{g+} / \Phi_{g 0}\right)=3$ and $\left(\Phi_{g-} / \Phi_{g 0}\right)=1 / 3$, the relation between $\left(R_{\mathrm{PM}} / R_{b}\right),\left(F_{\mathrm{dc}-} / F_{\mathrm{PM}}\right)$ and $\left(F_{\mathrm{dc}+} / F_{\mathrm{PM}}\right)$ can be obtained as listed in Table I. When selecting $\left(R_{\mathrm{PM}} / R_{b}\right)=7$, it results $\left(F_{\mathrm{dc}-}=F_{\mathrm{PM}} / 12\right)$ and $\left(F_{\mathrm{dc}+}=F_{\mathrm{PM}} / 4\right)$, indicating that the dc field winding excitation needs only $8.33 \%$ of PM excitation for flux weakening and $25 \%$ of PM excitation for flux strengthening to achieve 9 times change of air-gap flux.

\section{RESULTS AND VERIFICATION}

By using the FEM, the proposed machine is designed as listed in Table II. Fig. 2 shows its magnetic flux density distributions under flux weakening ( $F_{\mathrm{dc}}=-350$ A-turns), no flux control $\left(F_{\mathrm{dc}}=0\right)$, and flux strengthening $\left(F_{\mathrm{dc}}=+1000\right.$ A-turns $)$, respectively. The corresponding radial air-gap flux density distributions are shown in Fig. 3, which illustrates that a range of nine times of air-gap flux regulation can be realized. Fig. 4 shows the steady-state torque waveforms with and without flux control. It can be found that under the same starting current (two times the rated current), the developed average torque under flux strengthening ( $F_{\mathrm{dc}}=+1000 \mathrm{~A}$-turns) is about three times that without flux control. Hence, it verifies that the proposed machine can 


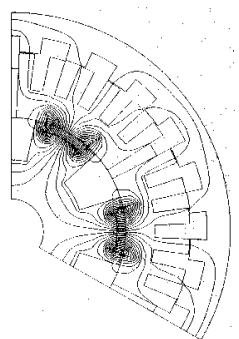

(a)

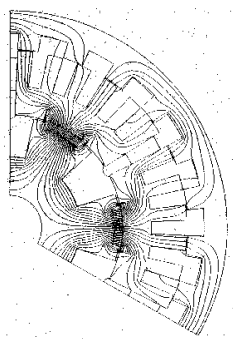

(b)

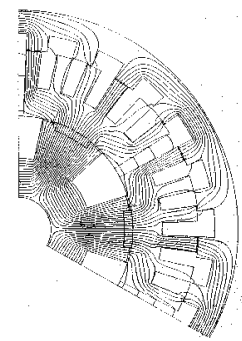

(c)
Fig. 2. Magnetic flux density distributions with different dc field excitations: (a) $F_{\mathrm{dc}}=-350$ A-turns; (b) $F_{\mathrm{dc}}=0$ A-turns; and (c) $F_{\mathrm{dc}}=+1000$ A-turns.

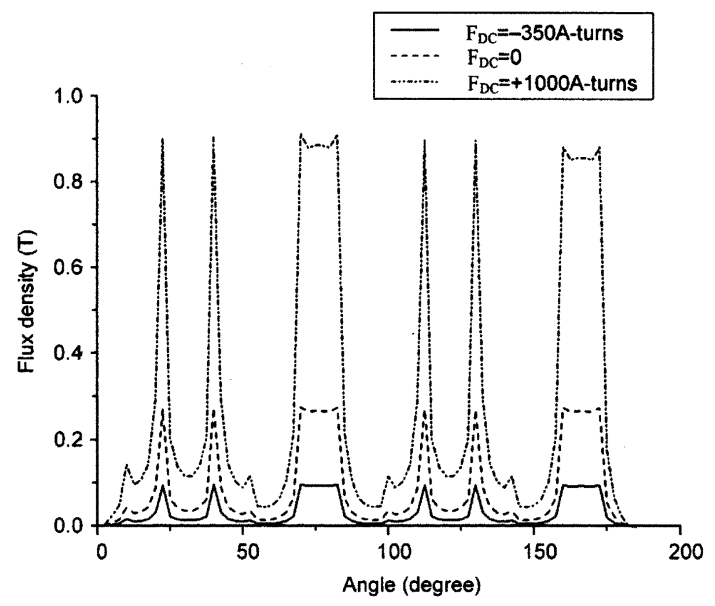

Fig. 3. Radial air-gap flux density distributions with different field excitations.

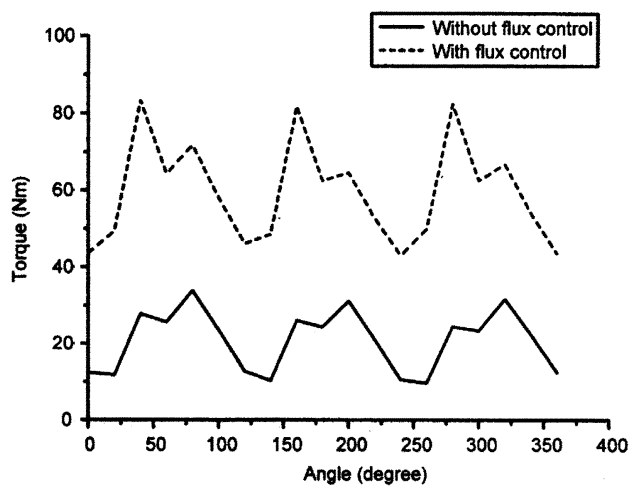

Fig. 4. Steady-state torque versus rotor position.

utilize its unique flux strengthening to significantly improve the starting torque for cold cranking.

Moreover, when the machine runs at different speeds of 400 , 1200 , and $3600 \mathrm{r} / \mathrm{min}$ without flux control, the corresponding no-load EMF waveforms are shown in Fig. 5(a). It can be found that the voltage amplitude varies significantly with different speeds. With the use of flux control (namely, flux strengthening at $400 \mathrm{r} / \mathrm{min}$ and flux weakening at $3600 \mathrm{r} / \mathrm{min}$ ), the proposed machine can maintain constant voltage outputs as verified by Fig. 5(b).

\section{CONCLUSION}

In this paper, a new outer-rotor SDF-DSPM machine for automotive engines has been designed and analyzed. Because of

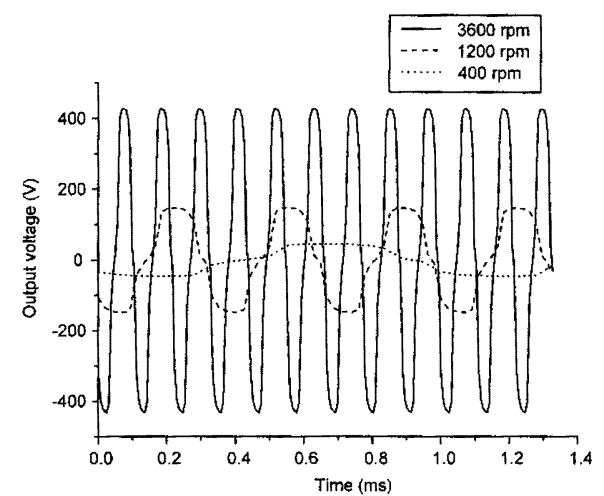

(a)

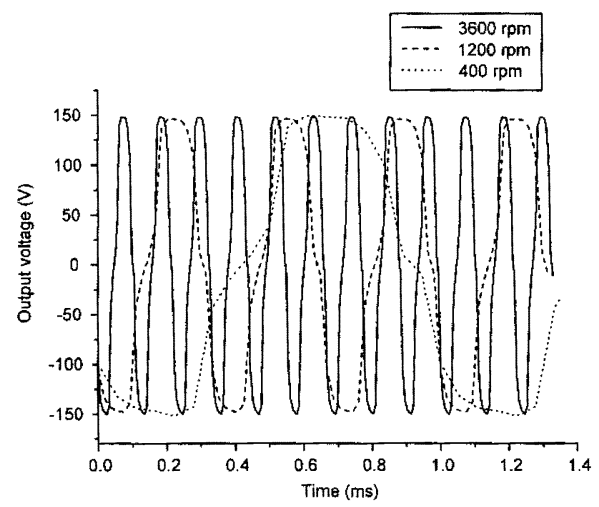

(b)

Fig. 5. No-load EMF waveforms at different speeds: (a) without flux control and (b) with flux control.

its capability of flux control, the proposed machine can realize a very wide range (nine times) of flux regulation, hence, achieving a high starting torque for cold cranking and maintaining a constant output voltage for battery charging. These two features are highly desirable for the machine to work as an ISG for modern automobiles and mild HEVs. The proposed machine has been evaluated by magnetic circuit modeling, finite element analysis and performance simulation to verify its unique features for ISG application.

\section{ACKNOWLEDGMENT}

This work was supported by the Research Grants Council of Hong Kong, China under Grant HKU 7114/06E.

\section{REFERENCES}

[1] A. Walker, P. Anpalahan, P. Coles, M. Lamperth, and D. Rodgert, "Automotive integrated starter generator," in Proc. Int. Conf. Power Electron., Machines Drives, 2004, pp. 46-48.

[2] A. M. EL-Refaie and T. M. Jahns, "Comparison of synchronous PM machine types for wide constant-power speed range operation," in Proc. IEEE IAS Annu. Meeting, 2005, pp. 1015-1022.

[3] K. T. Chau, J. Z. Jiang, and Y. Wang, "A novel stator doubly fed doubly salient permanent magnet brushless machine," IEEE Trans. Magn., vol. 39, no. 5, pp. 3001-3003, Sep. 2003.

[4] M. Cheng, K. T. Chau, and C. C. Chan, "Design and analysis of a new doubly salient permanent magnet motor," IEEE Trans. Magn., vol. 37, no. 4, pp. 3012-3020, Jul. 2001.

[5] K. T. Chau, M. Cheng, and C. C. Chan, "Nonlinear magnetic circuit analysis for a novel stator-doubly-fed doubly-salient machine," IEEE Trans. Magn., vol. 38, no. 5, pp. 2382-2384, Sep. 2002.

Manuscript received March 10, 2006 (e-mail: chualiu @eee.hku.hk). 